\title{
Implicit meanings: the addressee orientation in a communicative triad
}

\author{
Natalia Berezhnykh ${ }^{1}$, Natalia Kirichenko ${ }^{2, *}$, Tatiana Skopintseva ${ }^{1}$ and Ludmila Sludneva ${ }^{1}$ \\ ${ }^{1}$ Department of Foreign Languages, Irkutsk Transport University, 15, Chernishevskogo 664074 Russia \\ ${ }^{2}$ Department of Applied Linguistics, Irkutsk National Research Technical University, 83, Lermontova 664074, Russia
}

\begin{abstract}
The article presents the authors' insights concerning the problem of implicit meanings in its historic, cultural and linguistic aspects, as well as the needs of participants of communication in creating special conditions for interpretation and understanding of the message. The aim of the article is to introduce the notion of a communicative triad and its main constituents, such as "a proper addressee" and "a side participant'. Much attention is given to special means of creating informational insufficiency, i.e. erasing the connection between the significant and the signified (code mismatching), ambiguous pronoun reference, reference to the content of the shared experience. Of special interest are the cases where the targeted recipient of communication receives a semiotic complication of the utterance, as well as the metonymic transference based on the connection between what a speaker produces and the reality the proper addressee perceives. The following conclusion is drawn: all the described mechanisms are viewed as realization of a most essential property of human communication, i.e. its selective character which is achieved through various kinds of transformations of the reported utterance, so that it reaches its proper addressee in the form and size that would correspond to the communicative interests of the speaker.
\end{abstract}

\section{Introduction}

The understanding of natural language as the environment in which the processes of understanding are implemented suggests that one of its conditions should be the semantic transparency of the reported. In theoretical models of communication, the initial understanding is defined as a factor that determines the possibility of communication, and the achievement of mutual understanding is interpreted as its goal. In psycholinguistic framework, orientation to understanding the verbal expression is initially included in the process of speech generation [1]. Comprehensibility along with a number of other properties (truth, reliability), on the basis of which the concept of 'communicative rationality' is formulated, is included in the category of basic requirements to a linguistic expression in the theory of communicative action formulated by J. Habermas [2]. In a number of philosophical and cultural conceptions understanding between all participants of communication is proclaimed as its ideal [3].

In most cases, in the conditions of real communication, its participants deliberately resort to the production of so-called implicit meanings, which becomes possible due to special ways of organizing the reported text. These methods are based on various kinds of transformations of the reported, so that it reaches its recipient in a form and size that would correspond to the communicative interests of its sender.

\section{The problem of implicit meanings: historical, cultural and linguistic commentary}

Historically, the appeal to implicit meanings is implemented in a variety of cryptological systems. As an example, we can present the language of V. Maron (Vth century A.D.), Caesar's cipher, anagrams of Galileo, hieroglyphic form of writing in Ancient Egypt, capable of transmitting several types of messages at the same time, texts-palindromes, secret professional languages, literary method of "cryptography". It is a known fact that the operation of these systems was aimed at the implementation of specific goals in specific historical conditions, namely: the use of secret means of communication during the war, the struggle for scientific priority, the preservation of the secrets of professional skills, overcoming censorship prohibitions on the free expression of thought or due to the peculiarities of mythological thinking.

In the context of the modern world, the needs of the participants of communication in implicit meanings are interpreted much more broadly and are associated with the achievement of social and political power [4, 5], the desire to preserve institutional ideologies [6], the maintenance of a certain level of quality in the field of

\footnotetext{
* Corresponding author: author@e-mail.org
} 
science [7], "verbal self-defense" in totalitarian societies [8], maintenance of adequate communication within a separate discourse communities and echo subcultures, the need to follow the socially determined limitations on a range of speech acts [9]. Appealing to implicit meaning can be understood as the prevention of interference into the private space of a person, the protection of confidential information, as well as the desire for communicative leadership. The discrepancy between the categories of social and individual production of hidden meanings is aimed at reducing the cognitive dissonance.

The initial reflection of the ideas of the nature of implicit meanings is obtained in the works of philosophers dealing with the problems of ethics and aesthetics. Thus F. Bacon became one of the first who noted the property of natural language to be a source of implicit meanings. Later J. Locke wrote about the same features of the language, describing different ways of deliberately producing ambiguities (pseudonymy, lexemes of broad semantics, excessive imagery). Further the issue of hidden meanings (in a more traditional terminology - implicit) gets coverage in research papers of V. V. Vinogradov, N. D. Arutunova, M. V. Nikitin, A. I. Baranov. Factological material discovers that implicit meanings are manifested at all levels of the language structure, they permeate a variety of discourse types and are implemented in the communicative strategies. The problem of implicit meanings covers a wide range of phenomena - from hidden information in syntactic structures (resting on the principle of relevance) to the entire sphere of linguistic implication, including secondary designations, indirect speech acts, indirect speech genres, connotations, phenomena of ambiguity which cannot be clarified and understood from the context. The exceptional abundance of implicit meaning is characteristic of everyday colloquial speech. There is no generally accepted definition of implicit meanings today, however, the researchers agree that the lack of material expression does not mean that they can be judged as content without form; their main feature is thus being recognized as a result of the interaction of explicit values with the aggregate conditions of its implementation.

Modern linguistic and cultural theories suggest that any text created in a natural language initially contains implicit meanings. This thesis is consistent with the conceptions according to which any statement can be considered a parable, when an addressee understands not everything, and perhaps not in the way the author initially meant. It can be compared with the idea of infinite variation of meaning, the problem of its subjective inexpressibility and the conflict of interpretations as well as the ideas of the "incomprehensible" developed in philosophy, that is, "what we express is always something different from what we mean and what the statement refers to" [10].

Following the objectives of our work, it should be emphasized that under such conditions the phenomenon of implicit meanings is not dependent on the degree of their awareness by the participants of communication, and, what is more significant, on the sender of a verbal message. However, as noted above, the participants of the communication oftentimes conceal the sense of deliberateness and this is possible due to the special way of formatting the utterance (text).

\section{The notion of communicative triad: 'proper' and 'side' participants of communication}

The prototype of a communicative situation in which speakers deliberately create special conditions for the interpretation and understanding of the message can be considered the so-called communicative triad, organized by at least two heterogeneous categories of recipients. The latter are traditionally referred to as the "addressee" and are used for consideration of the communicative situation with two participants - the listener and the speaker without the possibility of appearance of the third party in them. However, the speech interaction between the two parties is fundamentally different from the interaction between several communicants (three in particular); adding the third to the diad has significant consequences and gives it special properties. Among them are the lack of strict rules of speech production order and a greater degree of conflict in connection with the aggravation of the struggle 'for the right to speak'. We assume that another feature of the communicative triad is the fact that it potentially implements a wider range of communicative roles of the addressee. Depending on the way of participation ("planned" or "random" addressee for the addresser) the category "addressee" can fall into a number of sub-categories, namely: "direct addressee", "indirect addressee", "eavesdropper", "casual listener". G. Clark was among the first to point out the possibility of having "random" participants in a communicative situation [11], denoting the latter as listeners who are not the members of the "the speaker's group" (i.e. "side participants of communicative process") (Ibid.). The above-mentioned ideas indicate that the categorization of the addressee in relation to the conditions under consideration requires different basis. Thus, the term "addressee" in the communicative triad corresponds to the particular recipient to whom a message is addressed directly. In this regard, we propose to denote this kind of addressee as "proper addressee", and "unplanned" participants of communication - real (within observability) or virtual (for example, in a situation where you are afraid that you can be eavesdropped) - "side" addressee.

The presence of side participants of communication (real or virtual) is regarded by members of the speaker's group as a kind of communication barrier which they seek to overcome. The practice of speech communication shows that speakers on any language have a fairly wide repertoire of ways to eliminate unplanned participants from communication (refusal to communicate, changing its space-time parameters, etc.). However, the need for a number of situational conditions in order to implement them (for example, a certain spatial location of speakers) encourages the search for other means, linguistic, in particular. In this case the purpose of communicants is to create information 
insufficiency of semantic and pragmatic nature for side addresses. The set of mechanisms used to achieve this goal can be defined as a kind of "text protection" - a type of communicative behavior realized, controlled and committed by a person in his own interests, expressed in a specific way of speech organization and providing the creation of special conditions for its interpretation and understanding.

To the semantic mechanisms considered in this article there belong code mismatching and the weakening of the relationship between the signifier and the signified. The pragmatic mechanisms include deliberately created ambiguity of the pronominal reference; production of semiotic heterogeneous texts; reference to the content of the joint experience of the speakers; metonymic transference. We'd like to emphasize that the designation of the boundaries between semantics and pragmatics is arbitrary and is undertaken solely for the purpose of analysis.

\subsection{Code mismatching. Erasing the connection between the signifier and the signified}

The most typical cases of code mismatching relate to the use of special lexical subsystems (argo, jargon) (according to R. Jakobson - "sub-codes" included in the "universal code"). The researchers indicate their special function, in different terminology - "conspiracy", "esoteric", "cryptoforic. In a number of theoretical works subcodes are interpreted from the standpoint of the idea of detachment [12]. Detachment is interpreted as a semantic category and is reduced to the thesis that the formation of the value of units of "sub-codes" occurs through the destruction of the familiar and the formation of new, comprehended "in their own, detached way" relationships between the sign and the object or phenomenon replaced by them. We believe that "detachment" can be interpreted in terms of communicative behavior, which is expressed through the use of specific units of definition, opposed to the universal code not only for the purpose of maintaining group exclusivity, but also for the purpose of the expulsion of side participants from the process of communication:

(1) "The Panda's got a monkey on her back.""Five, black curly hair, heavy moustache, aged forty, black overcoat, rubber-soled black shoes, Arab appearance."- "Stay on him," - came Monty's laconic reply. "Paul and Nancy stick with the Panda, you stick with monkey." - "Which floor?"- "One."- "Stay on him where he goes, keep talking to me." - "He could be carrying. "- "You mean he's pregnant?" [13].

In this example one Arab sheikh's wife gets the code name The Panda. Her security is provided by a group of special agents, one of them discovers that the protected object is under covert surveillance by alleged terrorists. Communication with the partner is carried out by means of a sub code, where the symbols - a monkey (=watcher's jargon: a mysterious follower); pregnant (=to be armed) are designed to ensure not only the efficiency and effectiveness of communication, but also its secrecy. Thus, the message organized in this way is characterized by high interactivity, and the text built on the basis of inherent designation systems becomes inaccessible to outsiders.

\subsection{Ambiguous Pronoun Reference}

The deliberately created ambiguous reference to the biological sex belongs to the mechanisms of pragmatics. In linguistics this method is described under the name ambiguous pronoun reference.

Our research shows that the absence of formal indicators of gender in English nouns can be consciously exploited. In particular, this may be due to the need to identify "Us" in some areas of socially prohibited behavior. The background of the conversation between two young women in the following example is the performance of one of them as a conferencier in an English pub:

(2) “...if she hasn't known she was a dyke, she'd never have guessed. Certainly, the boys on the front table couldn't tell either. The only hints were in a couple of jokes about 'My lover', where there was no specific reference to any form of personal pronoun ..."- "You are very funny."- "Thanks. That's the idea."- "You've got some great material."- "I saw you laughing. You're a good audience." - "I think I got some of the jokes.""Well, I would hope so."- "No, I mean some of the ones that went over the boy's heads."-"Well, they are pretty straight bunch, but I can usually spot the dykes in the audience - they get the subtle hints." - "Special code?" - "Something like this" [14].

The example above proves that ambiguous pronoun reference here is not so much a way of creating semantic uncertainty as it performs a password or coding function.

\subsection{Reference to the content of mutual experience}

The given mechanism of creating implicit meanings involves the examination of the epistemic (due to the shared experience of the sender and the addressee) aspect of hidden meanings.

The fact that participants of communication have shared knowledge, i.e. spontaneously arising "here and now" zones of individual cognitive spaces intersection not only increases the possibilities of orientation and understanding of verbal communication, but also, in some cases, acts as a necessary condition for reference.

In the following example, the expansion of understanding (reference to shared knowledge) is due to the lexeme "old", interpreted in the context as "familiar, known to me and to whom my message is intended" = "comprehended in our past experience":

(3) "Terrified of being separated from his family, Muhle shouted out to one he recognized on the other side of the cordon, a comrade from the mines."- "They are taking me. You must tell Nandi that I will see them in the old place" [15].

In the following piece the orientation of the listeners goes the same way: the commander of the special group 
performing a secret operation is instructed not to disclose information about the relocation sites. Before the next mission flight everybody is worrying about where they are flying this time. To ask such questions is prohibited by the manual, however, the platoon commander, feeling the mood of the soldiers, says "... it's going to be cooler where we're going." Keeping in mind that his soldiers know which country they have been the previous time, the new destination is "calculated" as "being more northern" [16].

\subsection{Creating the polycoding text}

In the field of oral communication, the orientation of the targeted recipient often receives a semiotic complication actualizing within two or more heterogeneous codes. In the cases under consideration the foregoing relates primarily to the non-verbal actions of the sender of the message carrying an open meaning exclusively for the targeted recipient. In terms of cognitive science, a similar way of conveying a message can be defined as a combination of linguistic and visual categorization capable of expressing a single meaning. At the same time, visual categorization acts as the main factor influencing the ability to understand semiotic heterogeneous formations:

(4) "Well? I think it's wonderful, the way David copes," said Mother. Lucy said, "Yes." They were walking along the cliff top. They took Jo, dressed in a fisherman's sweater and a fur coat. They had stopped at the top of a rise to watch David. ... Lucy could see in Mother's face an internal struggle between concern and discretion. She decided to save her mother the effort of asking. - "He doesn't love me," she said. Mother looked quickly to make sure, Jo was out of earshot. - "I'm sure it's not that bad, dear. Different men show their love in diff..." - "Mother, we haven't been man and wife properly - since we were married." - "But?" She indicated Jo with a nod. - "That was a week before the wedding" [17].

The additional code may be a tactile contact or a significant look, as, for example, in the following case:

(5) Confused, Langdon turned back towards Sophie, "I think you may have given me."- "No, that's the right number," Sophie interjected quickly as if anticipating Langdon's confusion. - "The Embassy has an automated message system. You have to dial an access code to pick up your messages."- Langdon stared. "But - It's the three-digit code on the paper I gave you." Langdon opened his mouth to explain the bizarre error, but Sophie flashed him a silencing glare that lasted only an instant. Her green eyes sent a crystal-clear message: "Don't ask questions. Just do it" [18].

\subsection{Metonymic transfer}

Another way of pointing the targeted recipient is the metonymic transference based on the connection between the speaker's statement and (perceived and perceived) reality. The following is the text of an encrypted telephone conversation between two criminal leaders. It indicates the details of the upcoming meeting. Encrypted objects are the participants of the meeting and the method of their movement. The first are given code names: Subject Echo, Subject Alpha, Subject Golfand, Subject Whiskey; the method of transportation is nominated through a more complicated way:

(6) "Who will come?"- "Subject Echo cannot attend. Subject Alpha, Subject Golf, and Subject Whiskey. How is your security?"- "Friend, we could hold off a regiment there, and my helicopter is always ready. How are you coming? Your great feet" [16].

In addition to designating the method of transportation, the phrase "great feet" carries a number of additional meanings for the address recipient, which are reconstructed as follows: a large amount of explosives will be brought on the truck in order to kill criminal opponents.

\section{Concluding Remarks}

The creation of information insufficiency for an unaddressed recipient and orientation of the understanding of individuals belonging to the speaker's group in the conditions of the communicative triad is achieved by using the described mechanisms and can be considered as the realization of one of the most essential properties of human communication, i.e. its selectivity.

\section{References}

1. G. Skantze, A. Hjalmarsson, Towards incremental speech generation in conversational systems, Computer Speech \& Language (27, 1), 243-262 (2013)

2. Yu. Khabermas, Teoriya kommunikativnogo deistviya, Vestnik Moskovskogo universiteta (7: Filosofiya), 43-63 (1993) (in Russian)

3. K. Yaspers, Smysl $i$ naznachenieistorii (M., Respublika, 1994) (in Russian)

4. N. Fairclough, Intertextuality in critical discourse analysis, Linguistics and Education (4, 3-4), 269-293 (1992)

5. L. Chouliaraki, N. Fairclough, Language and Power in Bourdieu: On Hasan's "The Disempowerment Game”, Linguistics and Education (10, 4), 399-409 (1999)

6. K. D. Kang, Language and ideology: Althusser's theory of ideology, Language Sciences (70), 68-81 (2018)

7. V. I. Karasik, David Gillespie, Discourse Personality Types, Procedia - Social and Behavioral Sciences (154), 23-29 (2014)

8. C. Goddard, A. Wierzbicka, H. Fabréga Jr., Evolutionary semantics: using NSM to model stages in human cognitive evolution, Language Sciences (42), 60-79 (2014).

A. G. Stamou, Synthesizing critical discourse analysis with language ideologies: The example of fictional 
discourse, Discourse, Context \& Media (23), 80-89 (2018)

9. S. L. Frank, Nepostizhimoe. Sochineniya (M., Pravda, 1990) (in Russian)

10. H.H. Clark, Speech acts and hearer's beliefs (London, Academic Press, 1982)

11. C. Caffi, R. W. Janney, Towards a pragmatics of emotive communication, Journal of Pragmatics (22, Issues 3-4), 325-373 (1994).

12. J. Carre, The Secret Pilgrim (London, Coronet Books, 1991)
13. S. Duffy, Fresh Flesh (London, Library of Congress, 1999)

14. G. Foden, Ladysmith (London, Faber and Faber, 1999)

15. T. Clancy, Clear and Present Danger (Glasgow, Fontana, 1989)

16. K. Follet, Eye of the Needle (NY., Penguin Books, 1979)

17. D. Brown, The Da Vinci Code (London, Corgi Books, 2004) 